\title{
Correlating Self-Esteem and Academic Outcome
}

\author{
Feroz Correlating
}

University of Swat, Pakistan

Received Date: December 23, 2017; Published Date: January 17, 2018

*Corresponding author: Feroz Correlating, University of Swat, Pakistan; Email: ferozshah1111@gmail.com

\begin{abstract}
The study was aimed to analyze whether or not the self-esteem of students had any effect on their academic achievement, to correlate selfesteem and the academic outcome of undergraduate students at the University of Swat. A hypothesis was formulated that students with higher self-esteem level will have higher academic outcome. A total sample of 600 participants was selected randomly from various departments at the University of Swat. Out of the 600 participants, 360 were male and 240 were female participants having qualified at least four semesters. Rosenberg Self-esteem Scale (RSES) was used to assess the self-esteem level of participants. The students were also asked to mention their Cumulative Grade Point Averages (CGPA) from their previous semesters at the end of the RSES questionnaire. The CGPA of participants was correlated with their score on the RSES scale by applying the Pearson Correlation Coefficient test using the Statistical Product and Service Solutions version 21 (SPSS v21). Results showed that there was in fact a significant positive correlation $(r=0.551, p<0.02)$ between students' CGPAs and their score on the self-esteem scale. It was concluded from the results that students with higher self-esteem level had higher academic outcome.
\end{abstract}

Keywords: Self-esteem; Academic outcome; CGPA

Abbreviations: RSES: Rosenberg Self-Esteem Scale; PSS: Perceived Stress Scale; BASS: Body Area Satisfaction Scale; APA: American Psychological Association; CGPA: cumulative grade point average; GPA: Grade Point Averages; NDII: National Diploma

\section{Introduction}

Multiple researches have attempted to determine whether there is any relationship between students' academic performance and their self-esteem. For instance, Fink found in his study at statistically significant degrees that Students who were high in their self-esteem are amongst many things, readier for college work, made higher scores on achievement tests, and were more proficient in English than students who were low in their self-esteem. This being so, one would expect them to have higher academic outcomes than students with low self-esteem [1]. The term 'academic outcome' is one of the frequently used terms in educational articles and assessment within higher education. Academic outcome or academic achievement is the results of acquiring education, the full extent of academic potential to which a pupil, lecturer or academic institution can reach in order to achieve their educational targets. Student's grades or GPA (grade point average) is used to describe the student's academic outcome in most of the research studies. Like Junco 2012 used students' actual CGPA (cumulative grade point average) which was obtained from the university registry while Kirschner, Karpinski 2010 used the CGPA self-reported by the participants of the study.
Academic outcome depends on a group of various elements; each of them needs a full work of study. One's personal elements might include: goals, specific motivations, a variety of methodologies, intelligence quotients or IQ's, physical qualities, behavioral characteristics, and mental or emotional condition. All these characteristics or qualities play a crucial role in academic outcome, achievement or even failure. Self-esteem can be one of the main factors of academic outcome. Self-esteem means selfsatisfaction and feeling valuable Nathanael 2000. On the other hand, self-esteem means that how people think about and values themselves, how much self-worth they have and how much they like themselves and also whether they are satisfied and happy about their performance, especially what their feeling is about their social and educational status, and how much coordination is there between their ideal and real selves [2]. Self-esteem is a basic humanistic need which is absolutely vital for survival and fine, productive development.

A study done by Ras Bera investigated the relationship between self-esteem and the performance in academia, the real score attained in the exam by the students was given to the group of students while a score 10 times lower than the real score attained was given to another group. Results from careful analysis 
showed that self-esteem and the performance in academia had a direct relationship with each other Ras Bera 1990. Studies done by [3] show positive and significant relationship between selfesteem and academic standing. Results of some researches and studies show the role and importance of self-esteem to explain academic standing. Sheikh al Islam 2010 conducted a study to see if there is any relationship in self-esteem and academic standing. Conclusions from his research confirmed the wellknown fact that that there is a positive correlation between selfesteem and academic standing among the students. Another study was carried out by Gerardi in 2005. Results derived from Girardi's study quantitively demonstrated that there is a positive correlation between self-esteem and academic performance of participants. Results derived from the study of Banafshe and colleagues also showed a positively significant correlation and a strong relationship between self-esteem and academic standing of the participants in their respective undertaken study [4].

\section{Literature Review}

A great deal of other studies has also shown that the relationship between self-esteem and academic outcome is a positive one. Lane assessed and evaluated the correlation between self-efficacy, self-esteem, performance level at a previous time and other accomplishments, and especially the academic outcome among a selected sample of 205 postgraduate students. Subjects were given scales measuring accomplishments in the past, self-esteem, and self-efficacy at the beginning of trial, which would go on for a 15 -week period. Average grade or score attained by each student from the modules studied was considered as them ensure of performance. More than one regression results indicated a positive relationship between self-esteem and academic outcome [5]. A research study was conducted, which aimed to analyze self-esteem and its probable connection to academic performance of students in universities. Judging by the data seen in the results from a research on 370 students, a difference of significant amount was perceived in selfesteem among students of both genders respectively. However, the male students received higher scores on self-esteem scale than ( $\mathrm{t}=-2 / 12), \mathrm{p}<0.05)$ female students [6]. Mohammad highlights the correlation between self-esteem and academic performance in the high school students. The scales were provided to 100 student participants in Qaemshahr schools. The results show that there was a significant $(\mathrm{p}<0.01)$ positive correlation between self-worth and academic performance. The results show that self-esteem is a significant predictor of academic performance and that students who have high selfesteem would have a better academic performance than those with less self-esteem [7].

Another research was undertaken to assess the relationship among motivation for achievement, self-worth, locus of control and academic achievement of students from a University in Nigeria. The goal was to see the level of academic performance in university students which was affected by these various and different variables. 1355 men and women from the university's students participated in the research. Results from multiple regression analysis revealed that self-esteem is positively correlated with academic performance. Mental and sociological data gathered imply that a lack of motivation for achievement and low self-esteem, brings about a deficiency of interest for a higher academic performance, and makes one unable to contribute positively and effectively to global and even national development and progress $[8,9]$. Conducted a study comparing the Adolescent students in England and the United States and investigated for a relationship between their self-esteem and academic achievement. Data of both the statistical and qualitative nature from 86 North American adolescent males and females and 86 British ones was generated. For both samples, the results showed that a fall in self-worth was related to various identifiers of academic performance in the later year [9].

A research was accomplished the goal of which was to find out how exam anxiety and self-esteem can relate to academic performance. 250 students from National Diploma (NDII) of the federal Polytechnic were randomly selected subjects of the research. Two questionnaires were given to them which took approximately between forty (40) to forty-five (45) minutes. After the gathering of data from the participants through the scales, their Grade Point Averages (GPA) in previous year were also noted. This GPA's were correlated with the scores obtained from the questionnaires earlier applied. This study showed that on total, students with a lower magnitude of anxiety had higher GPAs than students with higher anxiety and that there was a positive correlation between self-esteem and academic achievement [10]. A study was conducted using a bi variate correlation design. Participants were the students from the United States International University situated in East Africa. It was hypothesized that if self-esteem of the students went up, then their academic success will also increase. A total of thirtyseven (37) students participated. A sample of the senior students was selected to examine whether their self-esteem had gone up and if this increase had any correlation with their academic success. The Self Esteem scale of Rosenberg was applied to measure the students" self-esteem state between their first year and their senior year to see any changes that may have occurred. The quantitative analysis of this research show that there was a positive relationship $(r=.048)$ between self-esteem and CGPA [11].

Literature review showed that there was a correlation between self-esteem and academic performance of students, and that the relationship was mostly a positive one, that the students with higher Self Esteem were more likely to show a higher academic achievement or performance in different regions of the world, which led to the idea and worth of the present study, that it was important to reaffirm the findings to see if they showed the same results from university of Swat's Students as they did from many other universities in the world. The current study is aimed to study the relationship between self-esteem and academic outcome among male and female students from 
the University of Swat. Based on previous researches conducted in the domain, the following hypothesis was constructed:

\section{Hypothesis}

Higher Self-esteem will be associated with higher and positive academic outcome.

\section{Method}

\section{Sample}

A random sample of 600 students from three different departments of the University of Swat was selected. In total sample of 600 participants, 360 were male and 240 were female students. Only those participants were selected who had completed at least four semesters and remembered their scores (GPA's) on each semester. These students volunteered for the study out of their own will and claimed to be honest in their responses. The sample was selected from the Department of Psychological Studies, Department of Plant Sciences and the Department of Animal Sciences.

\section{Instruments}

'Rosenberg's Self-esteem Scale' was used to measure the self-esteem of the participants. The Scale is a self-reported measure. The scale consists of 10 items which are answered through four-point Liker scale ranging from strongly agree to strongly disagree. The scale was scored according to the manual for the Rosenberg Self-esteem Scale. For measuring the academic outcome, questions about the GPAs of participants in their previous two semesters were added at the bottom of the questionnaire. The CGPA of last two semesters were to be taken to measure student's recent academic performance.

\section{Procedure}

A total sample of 600 participants was selected randomly from three different departments of the University of Swat. The participants were told about the purpose of the study. Before giving the questionnaire, the participants were guided about the procedure and instructions for filling the questionnaire. In such a way, the data was collected. After collection of the data, the scoring was carried out according to the procedure described in the manual of the self-esteem scale. The cumulative grade point average (CGPA) scores of the participants for their last two semesters were also calculated. The statistical analysis for approaching the results was done with the help of Statistical Product and Service Solutions version 21 (IBM SPSS v21) - A statistical Package application for Windows computer.

\section{Results}

For drawing conclusions of the study, statistical analysis was carried out with the help of SPSS. For a simple bivariate correlation, the participants score on the Self-esteem scale was correlated with their CGPAs in their previous two semesters by applying Pearson Correlation Coefficient. The results from this statistical analysis illustrated that there is a positively significant correlation between Students' Self-esteem and their academic outcome as the $\mathrm{r}=0.551$ with $\mathrm{p}<0.02$.

\section{Discussion}

The current study was conducted for the purpose to investigate if there is any relationship between students' selfesteem and their academic performance. Based on literature review, the following hypothesis was constructed: Higher Selfesteem will be associated positive academic performance. To investigate this hypothesis, a total sample of 600 was selected randomly from three different departments of University of Swat. The Rosenberg Self-esteem scale was used to measure students' level of self-esteem. The obtained score was correlated with students CGPA in their previous two semesters. The Pearson Correlation Coefficient test was applied to investigate the relationship using Statistical Product and Service Solutions. The obtained value of " $r$ " was 0.551 with $p<0.02$. This shows that there was a direct and good correlation between Self-esteem and academic performance. A similar study was conducted by Arshad and colleagues. The aim of their study was to correlate the selfesteem and academic outcome of students from university after a rise of multiple issues of behavior and education in Pakistan. A total number of eighty students were selected from G.C University in Faisalabad. These students were given Rosenberg Scale to assess self-esteem and Academic Performance Rating Scale to assess their academic performance. It was seen that there in fact was a significant correlation relationship ( $\mathrm{r}=0.879$, $\mathrm{p}<.01$ ) between self-esteem and academic performance of the students Arshad, Zaidi 2015.

Another research was conducted to see the relationship between self-esteem and student's academic performance among second year undergraduates from the Faculty of Health Sciences and the Faculty of Medicine. 220 undergraduate students were chosen as participants via systematic random sampling, using three scales - Rosenberg Self-Esteem Scale (RSES), the Perceived Stress Scale (PSS) and the Body Area Satisfaction Scale (BASS). The relationship between self-esteem correlating with academic performance was calculated using Pearson's correlation test and linear regression, it was concluded from the results that students with higher self-esteem have a better performance $(\mathrm{p}<$ $0.0005, r=0.32$ ) in their academic areas Yanti Rosli et al. 2011. In a research study conducted by Zimmerman, he identifies and studies key processes by which students can self-regulate their academic learning to a certain extent. This research was conducted to determine the correlation between academic achievement and the various variables such as: self-worth, anxiety, pessimism and optimism. The sample consisted of 400 participants from both genders who were students in the Basic Education College in Kuwait. The results of the study showed that there was a positive and significant correlation between academic achievement and both self-esteem and optimism although there were negative correlations between academic achievement and both pessimism and anxiety [12]. 


\section{Summary}

Multiple Studies have been conducted to see the relationship between self-esteem and students' performance academically. Self-esteem in other words mean self-worth or self-value that how much an individual think of oneself to be worthy and valuable and happy about their performance especially how they feel about their social and educational status, and how much difference is there between their ideal selves and real selves [8]. Several other researchers showed a positive correctional relationship between self-esteem and academic outcome. Fink found in his study at statistically significant levels that Students who had higher self-esteem also got higher scores on achievement tests. Studies done by [3] showed positive and significant relation between self-esteem and academic performance [3]. After going through the literature review it was hypothesized that higher self-esteem will be associated with positive academic outcome [13-19].

Keeping in view the above points, a total sample of 600 was collected from three different departments of University of Swat. Out of the sample, 360 were male and 240 were female participants. The Rosenberg Self-esteem Scale was used to measure the self-esteem of the participants. Participants were also asked about cumulative grade point averages CGPAs of their last two semesters. After collecting the data Pearson Correlation Coefficient test was applied with the help of computer program, Statistical Product and Service Solutions, to compare the score of the participants the self-esteem scale with their CGPA in last two semesters. The outcomes of the test supported the hypothesis that higher self-esteem will be associated positively with a higher academic outcome.

\section{Conclusion}

The purpose of the current study was to investigate if there is any relationship between self-esteem and students' academic outcome. After selecting a sample of 600 participants, collecting data and analyzing the data through SPSS using Pearson Correlation Coefficient, it was proved that there is a positive and significant correlation between self-esteem and academic outcome, that students with a higher Self Esteem has a positive academic outcome compared to the students with lower Self Esteem from various departments of Swat university.

\section{Compliance with Ethical standards}

\section{Funding}

This research was self-funded by the authors themselves. No additional funding was received from any company or organization. All procedures performed in this study were in accordance with the ethical standards of American Psychological Association (APA). The study involves only human participants who volunteered for this study and informed consent was obtained from them.

\section{References}

1. Fink J (1958) Personal communication to R E Bills. RE Bills Manual for the Index of Adjustment and value.

2. Husseini M, Dezhgam M, Mirlashadi Zh (2007) The Correlation of Self-Esteem and Academic Achievement of Rehabilitated Students of Tehran University of Well Being Science and Rehabilitation. Iranian magazine of training in medical science 7(1): 137-142.

3. Pourshafeyi H (1991) Studying the Relation between Self-Esteem and Academic Achievement of Senior High School Students of Qaen (MA thesis). Teacher Training University.

4. Banafshe Hasanvandi, Mohamad khaledian (2012) The Relationship of Emotional Intelligence with Self-esteem and Academic Progress. International Journal of Psychology and Behavioral Sciences 2(6): 231-236.

5. Lane J, Lane AM, Kyprianou A (2004) Self-Efficacy, Self-Esteem and Their Impact on Academic Performance. Social Behavior and Personality: an international journal 32(3): 247-256.

6. Sadaat M, Ghasemzadeh A, Soleimani M (2012) Self-esteem in Iranian university students and itsrelationship with academic achievement. Procedia -Social and Behavioural Sciences 31: p.10-14.

7. Mohammad A (2010) Relationship between Self-esteem and Academic Achievement amongst Pre-University Students. Journal of Applied Sciences 10: pp. 2474-2477.

8. Abdullah OE (2000) Relationship Among Achievement Motivation, Self-Esteem, Locus of Control and Academic Performance of Nigerian. The Nigerian Journal of Guidance and Counselling 7 (1): pp. 130-141.

9. Booth MZ, Gerard JM (2011) Self esteem and academic achievement: a comparative study of adolescent students in England and the United States. National Centre for Biotechnology Information 41(5): 629-648.

10. Akinleke OW (2012) An Investigation of the Relationship between Test Anxiety, Self Esteem and Academic Performance among Polytechnic Students in Nigeria. International Journal of Computer Applications 51(1): 47-50.

11. Twinomugisha SR (2008) The relationship between Self-esteem and academic achievement.

12. Zimmerman BJ (2010) Self-Regulated Learning and Academic Achievement. Educational Psychologist 25(1): 3-17.

13. Gerardi S (2005) Self concept of Ability as Predictor of Academic Success among Urban Technical College Students. The Social Science Journal, Journal of Educational Psychology 42(2): 295-300.

14. Hasanvand B, Khaledian M (2012) The relationship between accounting students' emotional intelligence (EQ) and test anxiety and also their academic achievements. International Journal of Psychology and Behavioral Sciences 2(6): 231-236.

15. Khaledian, Mohammad, Kheyrkhah, Zeynab, Gholizadeh, et al. (1391) The relationship of the self-esteem with the test stress and academic achievement. Sixth seminar of the Gilan students mental health.

16. McLeod SA (2012) Low Self Esteem.

17. Ostadian, Maryam, Soudani, Mansoor, Mehrabi zadeh honarmand, et al. (2009) The effects of group consulting in Ali's intellectual, emotional, behavioural on the girl students in secondary school grade of Behbahan.

18. Self-esteem FAQ (2014) National Association for Self-Esteem.

19. Sheykhol Eslami, Ali, Ebrahimi Ghavam, Soghra, Farokhi, Noor Ali (2010). The relationship of the patience and self-esteem with the students' academic achievement. Contemporary psychological quarterly. 


\section{Psychology and Behavioral Science International Journal}

This work is licensed under Creative Commons Attribution 4.0 License

DOI: 10.19080/PBSIJ.2018.08.555733
Your next submission with Juniper Publishers will reach you the below assets

- Quality Editorial service

- Swift Peer Review

- Reprints availability

- E-prints Service

- Manuscript Podcast for convenient understanding

- Global attainment for your research

- Manuscript accessibility in different formats ( Pdf, E-pub, Full Text, Audio)

- Unceasing customer service

Track the below URL for one-step submission https://juniperpublishers.com/online-submission.php 